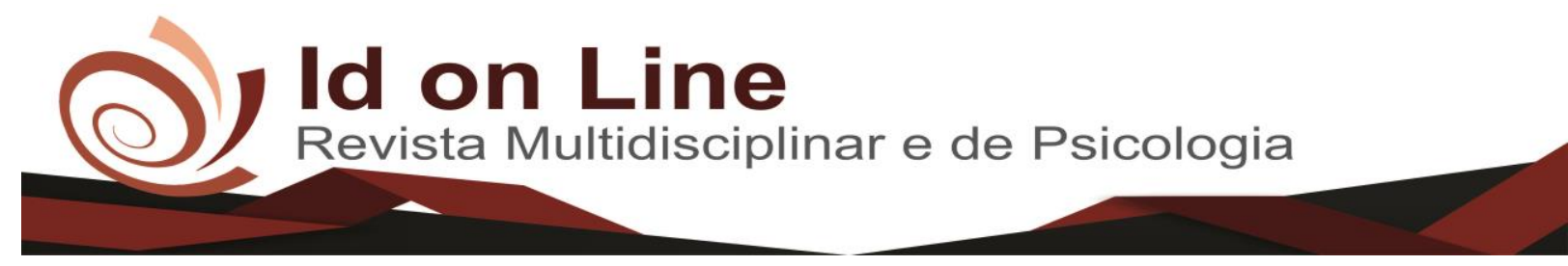

Artigo

\title{
O Papel Estratégico do Controller nas Organizações
}

\author{
Emanoel Romário de Lima $^{1}$; Maria Erilúcia Cruz Macêdo ${ }^{2}$
}

\begin{abstract}
Resumo: O esforço pelo desenvolvimento e eficiência na observância dos recursos, leva os responsáveis pela direção da entidade tomar decisões fundamentadas em dados consistentes, a obrigação de adquirir informações atualizadas, com projeções futuras e de fácil compreensão. Este trabalho justifica-se devido às contribuições que o controller pode apresentar à gestão empresarial, pois por meio de sua aplicação, os administradores serão capazes de obter informações fidedignas, dados mais precisos e confiáveis que lhe dão maior suporte nas tomadas de decisões. Dessa forma, o objetivo geral deste artigo foi apresentar a importância do controller na tomada de decisão para melhora no processo da gestão empresarial. Foi elaborada uma pesquisa bibliográfica, com intuito de referenciar conceitos, para obter o objetivo, foi realizada uma pesquisa descritiva, aplicando uma abordagem de forma qualitativa. É destacado na pesquisa, que são várias as contribuições que o controller pode proporcionar a organização, desde que seja de forma adequada e sempre dando maior suporte nas suas tomadas de decisões.
\end{abstract}

Palavras-chave: Controller, Gestão empresarial, Tomada de decisão.

\section{The Controller's Strategic Role in Organizations}

\begin{abstract}
The effort for development and efficiency in the observance of resources, takes the responsible for the management of the entity make decisions based on consistent data, the obligation to acquire updated information, with future projections and easy to understand. This work is justified due to the contributions that the controller can present to the management business, because through its application, administrators will be able to obtain reliable information, more accurate and reliable data that gives you greater support in decisions. Thus, The general objective of this article was to present the of the controller in decision-making to improve the process of business management. Was elaborated a bibliographical research, in order to refer concepts, to obtain the objective, a descriptive research was carried out, applying an approach of form qualitative. It is highlighted in the research, that there are several contributions that the controller can provide the organization, provided that it is properly and always giving greater support in their decision- making.
\end{abstract}

Keywords: controller, business management, decision-making.

\section{Introdução}

A globalização e as constantes mudanças que acontecem no mundo dos negócios têm guiado os gestores a procurarem possibilidades que verifiquem os resultados de suas práticas. Faz-se primordial, cada vez mais, dados que ajudem os gestores nas decisões a serem tomadas,

\footnotetext{
${ }^{1}$ Graduando do Curso de Bacharel em Ciências Contábeis do Centro Universitário Dr. Leão Sampaio - UNILEÃO. Email: e.romlima1991@gamil.com

${ }^{2}$ Orientadora Professora Especialista do Curso de Bacharel em Ciências Contábeis do Centro Universitário Dr. Leão Sampaio - UNILEÃO. Email: erilucia@leaosampaio.edu.br

684 Id on Line Rev. Mult. Psic. V.13, N. 43, , p. 684-697, 2019 - ISSN 1981-1179

684 Edição eletrônica em http://idonline.emnuvens.com.br/id
} 
e para que consigam ter informações fidedignas e controle do que transcorrem em todos os setores da entidade, é necessário que as empresas disponham de um sistema de controladoria a fim de que o controller possa proteger os ativos e analisar a exatidão e fidelidades dos dados contábeis com bastante eficiência.

Tendo como base o contexto apresentado, o trabalho procurou responder quais as contribuições que o controller incluso nas organizações pode oferecer a gestão empresarial para melhor desempenho de suas funções e consequentemente para as suas tomadas de decisões?

Com isso, o presente artigo teve como objetivo geral apresentar a importância do controller na tomada de decisão para melhora no processo da gestão empresarial. Foram definidos como objetivos específicos, identificar as características da função e papel do controller e analisar como os processos do controller podem contribuir para um melhor desempenho das organizações.

A execução do trabalho se deu presente através de uma pesquisa bibliográfica, constituída com suportes em materiais publicados, com característica descritiva, adquiridas através de propor opiniões, atitudes e crenças de uma população e por fim uma abordagem qualitativa onde assegura aplicações de analises de quesitos relacionados ao estudo.

A definição deste tema se deu devido às contribuições que o controller pode apresentar à gestão das organizações, pois por meio de sua aplicação, os administradores serão capazes de obter informações fidedignas, dados mais precisos e confiáveis que lhe dão maior suporte nas tomadas de decisões, possibilitando proteção a tudo relacionado à entidade e mais incentivo nos componentes das políticas organizacionais.

Assim, a controladoria como instrumento de suporte a gestão, propicia sugestões e condições que sejam aptas de solucionar a fragilidade das entidades em tempos adversos e de obstáculos, com o intuito de aperfeiçoar suas receitas, utilizando menos gastos de uma maneira mais consistente.

\section{Referencial Teórico}

\section{Controladoria}

A controladoria é um conhecimento autônomo que utilizar-se de todo o conjunto da ciência contábil incluso da organização e compete a ela ser responsável pelo desenvolvimento e aplicação de métodos, já que a contabilidade é a ciência de todos os aspectos temporários. 
Contudo, Bermudo e Vertamatti (2016, p. 18) demonstram que "Isso deve-se ao fato de a Controladoria ser uma disciplina relativamente nova que vem buscando, ao longo dos anos, sua própria identidade e definição quanto ao escopo de sua atuação.".

Logo, em se tratando de controladoria, Nascimento e Reginato (2015) estabelecem como um ramo do conhecimento onde está direcionada para analises elaboradas através de teorias e temas que proporcionam ao controller a diversidade dos métodos decisórios e as próprias características da compreensão dos gestores, possibilitando uma melhor forma de tomada de decisões.

De acordo com Padoveze (2003), a controladoria consistir em ordenar o desenvolvimento da organização e se sobressai formando uma estrutura que se divide em duas áreas, a contábil e fiscal que faz toda analise e correção de suas contas ativas e passivas, e finaliza com o balanço patrimonial junto com o setor financeiro, a outra área é a do planejamento que é como um campo no qual procura estratégias para desenvolver projetos ao crescimento da empresa, mas para que esse plano seja feito tem todo o apoio do controle, pois ele é quem discorre e elabora todos esses suportes estratégicos.

Para um melhor entendimento sobre o controle elaborado dentro das organizações e com o intuito de resultados esperados, Gonçalves e Riccio (2009) definem a controladoria como setor principal responsável da gestão econômica, onde se encontra embutida à implantação de princípios, políticas e conceitos dessa coordenação econômica, além da necessária assimilação dos seus respectivos objetivos e o desenvolvimento mais favorável dos resultados econômicos globais.

A controladoria atuando como órgão administrativo empresarial tem como missão, segundo Catelli (2001, p. 346) "assegurar a otimização do resultado econômico da organização na busca pela eficácia institucional, de forma a possibilitar o crescimento dos ganhos corporativos, por meios de decisões assertivas".

Para Mossimann e Fisch (1999), a missão da controladoria é assegurar que a entidade prossiga com seus procedimentos futuramente por meio do fornecimento de informações integras e tempestivas, da direção econômica e da inserção de todas as áreas que constituem o sistema empresarial, e consequentemente a obtenção dos objetivos da organização.

No entanto, a missão da controladoria para elaboração dos métodos de gestão, de acordo com Nascimento e Reginato (2009), apresenta que além dos conhecimentos fundamentais apresentados por aplicação de um sistema de informações, esses processos realizam essas tarefas, demonstrando assim a informação a ser útil, devera também ser confiável. 
Com o auxílio das diversas gestões das organizações, Oliveira, Perez Jr e Silva (2010) abordam quanto ao papel da controladoria, estabelece o processamento de informações, interpretando e repassando aos respectivos responsáveis, por meio de visão sistêmica, disponibilizando auxilio na procura por decisões assertivas que proporcionem a sustentabilidade da entidade e facilitando no processo decisório.

Já as funções da controladoria estão de modo direto associadas à sua missão, pois surgem com objetivo de fornecer contribuição na obtenção da mesma. Contudo, Perez Jr., Pestana e Franco (1997) retratam a atuação da controladoria influenciando de forma notável no processo decisório, por interferências de informes do controle e planejamento, portanto, as funções proporcionam dados para seu cumprimento com o intuito de alcança os planos estabelecidos.

A controladoria exerce em cada área da empresa suprindo as obrigações específicas de gestão de cada empresa. Segundo Peleias (2002) Observa-se que as funções da controladoria são estabelecidas de acordo com a necessidade de cada entidade. Compete à gestão adequar essas funções conforme os objetivos da empresa, sendo assim, algo satisfatório para os resultados desta área.

Portanto, conforme Guerreiro (2000), o desafio contínuo da controladoria é determinar informações que possibilitem aos gestores concentrarem-se nas suas funções, exercendo isto, eles gerarão exatamente o que é fundamental para a organização conseguir seu principal objetivo que é a geração de lucros.

Percebe-se que a controladoria é uma área que determina pelo meio de sistemas de informações gerenciais os aspectos sobre gestão contábil e financeira, entretanto é significativo especificar que ela não substitui o cargo do gestor, pois, apesar de que a controladoria tenha um dever considerável dentro das empresas, compete ao administrador à tomada de decisão.

\section{Controle Interno}

A respeito do controle interno na execução dos processos elaborados dentro das organizações, Figueiredo (2004), trata como uma área que trabalha com o feedback, ele dar início a todo procedimento avaliando seus pontos positivos e negativos, buscando estratégias para um bom desempenho empresarial, passando assim para os outros setores que fazem a análise dos sistemas que finalizam todo o trabalho desejado. $\mathrm{O}$ mesmo é o foco do desenvolvimento enquanto que sua finalidade no processo de idéias através do planejamento 
mediante curto, médio e longo prazo, desempenhando o papel que a empresa precisa no intuito de convencer e ampliar no atual mercado.

Nota-se que por meio de informações fidedignas e baseadas em critérios adotados dentro das organizações, Crepaldi (2004) demonstra que o controle interno são todas as medidas adotadas pela organização para resguardar o patrimônio, o mesmo caminha agrupado com o planejamento, desenvolvendo assim os trabalhos antes planejados, quando bem elaborados, torna as atividades mais claras de avaliar e de controlar, proporcionando a exatidão e fidedignidade das demonstrações contábeis, auxiliando assim na tomada de decisões e fiscalização de possíveis práticas de fraudes e erros.

No entendimento de Chiavenato (2004) em acordo com o aperfeiçoamento dos resultados adquiridos nas organizações, apresenta o controle como um método administrativo que tem como finalidade certificar que o que foi executado seja de acordo com o planejado e permite que a organização avalie se os seus objetivos, antes definidos, estão sendo seguidos e apresentando bons resultados.

O controle interno sendo determinado como uma etapa de processos administrativos busca, conforme Barreto (2008), garantir a continuidade e integridade da empresa pelo reconhecimento em tempo hábil precauções corretivas, em relação de irregularidades detectadas, e por uma reformulação das metas estabelecidas, em conseqüência das alterações observadas na dinâmica interna e no contexto externo.

Para que a empresa tenha uma proteção em relação aos riscos que possam eventualmente aparecer, Attie (2010) mostra que o controle interno é de grande importância, tornando todas as decisões a serem tomadas como objetivos de melhorias nos processos gerados pela entidade, na inibição de erros e fraudes e com um grau de confiabilidade maior na segurança das informações.

Contudo, Almeida (2012) evidência em relação à importância que o controle interno tem dentro da empresa, no qual afirma que esse controle vem para auxiliar com dados contábeis transparentes, sendo assim, seus gestores consigam alcançar conhecimentos eficientes para que venha a conduzir de maneira organizada a entidade.

Assim sendo, o controle interno atinge todos os meios programados numa entidade para dirigir, restringir, governar e conferir suas diversas tarefas com a finalidade de realizar os objetivos. Portanto, nota-se o quanto o controle interno apresenta benefícios para a gestão e desenvolvimento da organização, pois ao se constitui, a empresa tem a obrigação de ter um dispositivo de sustentação para que seus objetivos sejam executados. 


\section{Controller}

Em se tratando de controller, Garcia (2010) demonstra que ele tem papel importantíssimo no suporte aos gestores da organização na elaboração das melhores práticas de controle, pois o mesmo tem interesse em determinados controles que sejam desempenhados da melhor maneira possível, para garantir conhecimentos com integridade, possibilitando assim, um apoio para a contabilidade.

Entretanto, para estabelecer o apoio aos gestores de forma a possibilitar o maior controle, Figueiredo e Caggiano (2008) identificam o controller como o responsável da contabilidade, aquele que supervisiona de modo a manter os documentos financeiros protocolares da empresa, ainda que suas funções não tenham que se restringirem somente a funções contábeis e ao mesmo tempo espera-se que ele expanda sua atuação ao desenvolvimento da contabilidade em aproveitamentos de caráter gerencial.

Nos dias atuais, é extremamente importante para os indivíduos das organizações manterem a sua ética profissional estabelecidos em seus padrões, pois segundo Srour (2008), mostra que a conduta do controller deverá ser proporcional ou ainda maior a sua devida responsabilidade, pelo fato de estar sobrecarregado com dados da entidade onde atua, sendo assim essencial o zelo e o bom uso das informações, portanto, o profissional da controladoria tem autonomia de opinar nos processos de decisão das empresas por motivos dos seus conhecimentos processados.

Com o crescente desenvolvimento da tecnologia e a modernização das organizações com o sistema de informação nos dias atuais, Oliveira, Perez Jr. \& Silva (2002) ressaltam que para enfrentar os novos obstáculos, o controller deve apresentar novas técnicas, como práticas internacionais de negócios, controles orçamentários e planejamento estratégico. Aponta também que o controller deve ser um profissional de fácil relacionamento e bastante hábil para negociar suas idéias.

Dessa forma, para um bom desempenho do controller, Figueiredo e Caggiano (1997) consideram que o profissional deve estar atento as questões que no decorrer das suas tarefas possam vir a surgir na empresa, ser versátil, para que esteja pronto a dificuldades encontradas e sempre buscando se atualizar para adquirir um maior aperfeiçoamento profissional.

Logo, Nakagawa (1993) fala que o desempenho das funções do controller é essencial dentro das organizações, pois ao providenciar e atribui informações relevantes desempenham uma influência que leva aos gestores a tomarem decisões junto à missão e objetivos traçados 
pela organização, assim o controller é atribuído para geração de dados do sistema integrado da empresa.

Portanto, com as exigências muito mais complexas para as atividades do profissional da controladoria, o controller devera realizar inúmeras tarefas e ter diversos conhecimentos. Com isso, Oliveira, Perez e Silva (2004) relatam que esse profissional precisará ser multifuncional, ou seja, deverá ele, acrescer suas experiências não só em sua área, mais nos múltiplos campos de atuação dentro e até mesmo fora das organizações.

Com isso, percebe-se que o controller finda sendo o encarregado pelo esboço, elaboração e aperfeiçoamento de um sistema integrado de informações, que prepara o conceito da controladoria como ferramenta fundamental. Constata-se então, que o controller tem papel essencial no suporte aos gestores, conduzindo os trabalhos no alcance da eficácia em prol de melhores resultados para a empresa.

\section{Controladoria Estratégica}

Para um entendimento a respeito do proposto, Oliveira (2010) demonstra que no meio organizacional, estratégia é uma maneira de estabelecer metas para que no futuro à entidade esteja preparada para eventuais obstáculos, mostra também que é uma tarefa que está inserida no processo decisório das empresas e que deve compreender o conhecimento do seu segmento e a constatação organizada de seus aspectos, para que através de ações possa manter e desenvolver vantagens competitivas.

Em relação à controladoria estratégica inserida dentro das organizações executada através dos profissionais capacitados a essa função, onde é ajustada por Padoveze (2010), como um parâmetro da controladoria que pelo meio do sistema de informação contábil, fornece aos responsáveis pelo planejamento estratégico da organização com dados financeiros e não financeiros, para sustentar o processo de análise, planejamento, implementação e controle da estratégia organizacional, podendo assim, os administradores terem maior suporte nos momentos das decisões a serem tomadas.

Para o desenvolvimento das organizações junto à controladoria estratégica, é de extrema importância um planejamento a cada processo a ser elaborado, promovendo assim, de acordo com Nascimento e Reginato (2015), a eficácia das decisões, o acompanhamento na execução dos objetivos traçados, e principalmente, amenizando para os gestores sobre as situações das variações econômicas, através do fornecimento de informações de operações passadas em 
relação às presentes estabelecendo assim um controle dos processos e da sua própria comunicação, de maneira a fortalecer a integridade das organizações nas tomadas de decisões.

Com isso, a controladoria estratégica vem obtendo grande espaço dentro das empresas devido à alta dificuldade de controle que os gestores necessitam para competir no mercado, já que se encontra em constante transformação, portanto, Santos e Schmidt (2006) determinam que, a controladoria é como ferramenta essencial para o planejamento estratégico das organizações, estando responsável pela eficiência financeira do desenvolvimento de ótimos resultados estabelecidos por parte das decisões dos gestores em relação à empresa.

A aplicação dos recursos da controladoria é indispensável para oferecer, confiabilidade, eficácia, segurança e agilidade no desenvolvimento de dados para processos decisórios. Assim, Oliveira, Perez Jr e Silva (2010) certificam que a controladoria estratégica, desde o seu planejamento, passando por avaliações de desempenho, orçamentos, planos de ação e a eficiência nos aprimoramentos dos processos iniciais são fundamentais para um prosseguimento empresarial auto-sustentável.

Nestes contextos, a controladoria estratégica encontra-se nas organizações principalmente para simplificar aos gestores o desenvolvimento e a efetivação da estratégia empresarial, para que os administradores mantenham o foco em seu respectivo estabelecimento, tendo assim, a visão de um todo.

\section{Gestão Empresarial}

Segundo Maranhão e Macieira (2008), retratam que no decorrer dos anos a gestão empresarial segue um tratamento prático e de certa forma efetuando seus objetivos, passando a ter clareza das cadeias produtivas e das próprias entidades. Entretanto, com o crescimento da diversidade dos métodos empresariais e o aperfeiçoamento da agilidade junto à informação, esta característica deixou de realizar seu principal objetivo, ou seja, a gestão do negócio, não atuando mais com eficácia como um procedimento para esclarecer as principais obrigações empresariais.

Logo, Matarazzo (1998) demonstra que a gestão caracteriza-se pelo comportamento em padrão interno da entidade que busca desenvolver as suas relações, considerando os fatores dos ambientes externo e interno que atingem as atividades da empresa, em seus pontos econômicos, financeiros, operacionais e patrimoniais. 
A gestão empresarial não se limita apenas em tomar decisões, com isso, esse processo é caracterizado em planos projetados, com bases nos conceitos estipulados no modelo de gestão. Contudo, Figueiredo e Caggiano (1997) constatam que as decisões tomadas por as empresas deveram ser asseguradas para realização da missão, proporcionando assim, a continuidade da organização.

Os modelos de gestão são procedimentos que vão nortear os gestores na definição das melhores possibilidades para administrar as entidades. No entendimento de Pereira e Santos (2001, p. 47), o modelo de gestão "é compreendido como o conjunto de princípios, técnicas e explicações que orientam a concepção e o modo de funcionamento de todos os elementos constituintes de uma organização.”.

Para obter um conhecimento a respeito do modelo de gestão, Nascimento e Reginato (2010) estabelecem esse modelo como uma estrutura da empresa, por isso deverá ser realizada estrategicamente, pois quanto mais efetuação deles, o sistema de controles internos será eficaz e eficiente, obedecendo assim seu papel de fornecer a controladoria com esclarecimentos confiáveis que possam garantir a conduta ética e o cumprimento das atividades dos colaboradores dentro das organizações.

Percebe-se então, que a gestão empresarial por ser um composto de procedimentos e estratégias utilizadas em um determinado empreendimento, facilita aos gestores na administração dos seus negócios, pois no mundo cada vez mais competitivo, dinâmico e em progressiva mudança é essencial que a gestão empresarial seja assertiva.

\section{A Controladoria como Suporte ao Desempenho das Organizações}

Conforme o desenvolvimento das atividades executadas diariamente por parte da controladoria, Oliveira (1998) demonstra que esse setor organizado estar capacitado para que o desempenho dos administradores melhore em relação à eficácia e eficiência da empresa, através do monitoramento dos controles gerenciais e na detecção de possíveis limitações em outros setores, podendo assim, por meio de deficiências encontradas ficarem mais acessível para que cada setor crie medidas necessárias para solucionar os problemas.

Sob esse ponto de vista, Garcia (2010) retrata que a controladoria através do desempenho do controller, é responsável pela a preparação e implemento de um sistema interligado de informações financeiras e operacionais, baseados e elaborados em estruturas consistentes de controles internos através das demonstrações contábeis, suprindo assim os 
gestores com ferramentas de análise e controle gerencial e consequentemente, permitindo a obtenção dos objetivos organizacionais traçados pela alta administração, ou seja, o corpo dos dirigentes máximos da organização.

Para Figueiredo e Caggiano (2008), com a procura da eficácia organizacional o envolvimento da controladoria deverá exercer um desempenho bem profundo em relação a isso, portanto, precisara de um suporte a ser elaborado e para alcançá-la, é fundamental que sejam estipulados modelos com eficiência para conduzir o cumprimento de suas obrigações.

Em relação à área de conhecimento da organização Gonçalves e Riccio (2009), estabelecem que a controladoria tenha o papel da contabilidade de verificara formação de valor dentro da organização, e ainda resulta em estudos apontados a modelos de gestão e melhores atributos de satisfazer às necessidades de informações gerenciais e estratégicas da organização. Assim sob a perspectiva de sua atuação dentro de uma entidade, a controladoria compreende suas funções e atividades, que o desempenho dos seus sistemas de informações seja praticamente tão amplo quanto o próprio sistema de informação de apoio operacional e gerencial.

A controladoria estabelecida como ramo do conhecimento desenvolve plataformas, segundo Nascimento e Reginato (2015), culturais, teóricas e filosóficas que proporciona a todos os setores da instituição com o suporte de ferramentas apropriadas para sua função, agregando assim, valor ao ramo da organização. Além disso, a controladoria através das suas tarefas procura satisfazer todas as necessidades dos seus clientes internos.

Em se tratando do desempenho extraído pela controladoria, é proporcionado por um especialista para estabelecer total suporte a organização, com isso, Padoveze (2016) demonstra que esse profissional deverá atuar pelo caminho trilhado por informações contábeis, atuando diariamente para obter resultados sobre os processos determinados nos planejamentos elaborados, contribuindo na mensuração e principalmente na otimização da tomada de decisões por parte dos administradores.

Portanto, a controladoria como suporte das organizações tem um importante propósito de planejar, elaborar e executar um sistema na sua estrutura organizacional, assegurando que seus dados sejam expressivos, chegando assim nos resultados pretendidos, e através do seu desempenho, garantir que seus usuários possam ter informações confiáveis e em tempo hábil. 


\section{Metodologia}

No presente estudo aplicou-se de uma pesquisa bibliográfica, com características descritivas e uma abordagem qualitativa mediante materiais escritos e publicados, como livros e artigos para observação do que já foi gerado sobre o tema proposto em estudos e através de pesquisas a serem utilizadas no trabalho executado, a fim de certificar os resultados encontrados em relação ao que foi apresentado pelo tema deste artigo.

Com relação à pesquisa bibliográfica, Gil (2010) retrata que ela é constituída com suporte em materiais já publicados, com o intuito de pesquisar inúmeras posições em relação a determinados conteúdos, utilizando-se de livros, artigos, periódicos e internet como materiais a serem usados no tema proposto.

Considerando os objetivos definidos, a pesquisa é realizada por meio de características descritivas, pois descreve os processos de controladoria como suporte para as organizações. Segundo Gil (2010), a pesquisa descritiva tem como principal finalidade a definição das características de determinados grupos e identifica prováveis variações no instrumento de estudo. São pesquisas que tem propósitos de propor opiniões, atitudes e crenças de uma população.

Com o intuito de obter resultados sobre o tema e alguns tópicos a serem estudados, foi aplicada uma pesquisa qualitativa, que conforme Marconi e Lakatos (2011), explica que tem uma área natural como fonte direta de informações e o pesquisador como seu principal mecanismo. A utilização dessa abordagem assegura a aplicação da análise de quesitos relacionados ao fenômeno em estudo e das suas relações.

\section{Considerações Finais}

O presente trabalho procurou certificar a aplicação da controladoria determinada pelo controller como ferramenta estratégica na gestão empresarial, e com suporte nos estudos desempenhados, demonstrou a relevância da controladoria no gerenciamento organizacional.

O profissional da controladoria para toda organização é de grande importância pelo motivo que o mesmo possa prevenir irregularidades na execução das atividades de qualquer entidade. É fundamental que esses profissionais possam acrescentar confiabilidade aos resultados dos procedimentos para que os objetivos elaborados pelos gestores sejam alcançados. 
Dentre inúmeros aspectos abordados, observa-se que o controller, profissional que é encarregado por exercitar a controladoria nas entidades, constituindo sistemas que são voltados às propensões da organização nos processos estabelecidos.

Este trabalho foi desenvolvido com o propósito de compreender quais as contribuições que o controller incluso nas organizações pode oferecer a suas gestões, pois quando uma entidade utiliza os métodos de controladoria e faz um acompanhamento contínuo, assim a empresa tem mais possibilidades de preservar seus ativos, buscando um maior desempenho na obtenção das tarefas planejadas e evitando que ocorram eventuais problemas.

Ao final deste trabalho nota-se que o objetivo proposto foi alcançado, pois é capaz de interpretar a real importância da controladoria nas organizações, esta que fornece dados instruídos de nortear a tomada de decisão, para que a entidade seja capaz de assegurar a competitividade no atual mercado, atingindo o êxito gerencial e com isso alcançando efetivamente suas metas e objetivos planejados.

Portanto, o trabalho constituiu-se em um estudo com base em fontes já publicadas e o estímulo dado não finalizou o tema, mas obteve uma conclusão de que o objetivo da pesquisa e da exposição de conhecimento é fundamental para o desenvolvimento das pessoas. É esperado que este trabalho colabore um pouco para o estudo da controladoria e para o conhecimento do seu respectivo profissional, pois ele é essencial para a gestão das organizações.

\section{Referências}

ALMEIDA, Marcelo Cavalcanti. Auditoria: um curso moderno e completo. 8 ed. São Paulo: Atlas, 2012.

ATTIE, William. Auditoria. Conceitos e Aplicações. 5 ed. São Paulo: Atlas, 2010.

BARRETO, Maria da Graça Pitiá. Controladoria na Gestão: a relevância dos custos da qualidade. São Paulo: Saraiva, 2008.

BERMUDO, Vera; VERTAMATTI, Roberto. Controladoria Estratégica e seus desdobramentos comportamentais: a SOX como apoio à geração de valor organizacional. São Paulo: Atlas, 2016.

CATELLI, Armando (Coordenador). Controladoria: Uma Abordagem da Gestão Econômica GECON. 2 ed. São Paulo: Atlas, 2001.

CHIAVENATO, Idalberto. Introdução à teoria geral da administração: uma visão abrangente da moderna administração das organizações. 3 ed. Rio de Janeiro: Elsevier, 2004. 
CHIAVENATO, Idalberto; SAPIRO, Arão. Planejamento Estratégico: fundamentos e aplicações. $6^{\mathrm{a}}$ ed. Rio de Janeiro: Campus, 2003.

CREPALDI, Silvio aparecido. Auditoria Contábil: teoria e pratica. 3 ed. São Paulo: Atlas, 2004.

FIGUEIREDO, Sandra. Controladoria: teoria e pratica. 3 ed. São Paulo: Atlas, 2004.

FIGUEIREDO, Sandra; CAGGIANO, Paulo Cesar. Controladoria: teoria e prática. 2 ed. São Paulo: Atlas, 1997.

Controladoria: teoria e pratica. 4 ed. São Paulo: Atlas, 2008.

GARCIA, Alexandre Sanches. Introdução à Controladoria: instrumentos básicos de controle de gestão das empresas. São Paulo: Atlas, 2010.

GIL, Antonio Carlos. Como elaborar projetos de pesquisa. 5 ed. São Paulo: atlas, 2010.

GONÇALVES, Rosana C. M. Grillo; RICCIO, Edson Luiz. Sistema de Informação: ênfase em controladoria e contabilidade. São Paulo: Atlas, 2009.

GUERREIRO, Reinaldo. Modelo conceitual de sistemas de informação de gestão econômica: uma contribuição a teoria da comunicação da contabilidade. São Paulo: USP, 2000.

MARANHÃO, Mauriti; MACIEIRA, B. Maria Elisa. O processo nosso de cada dia: modelagem de processos de trabalho. Rio de Janeiro: Qualitymark, 2008. Disponível em:http://www.convibra.com.br/upload/paper/2012/39/2012_39_4866.pdf. Acesso em: 21 set 2018.

MARCONI, Marina de Andrade; LAKATOS, Eva Maria. Metodologia do Trabalho Científico: procedimentos básicos; pesquisa bibliográfica, projeto e relatório; publicações e trabalhos científicos. 7 ed. São Paulo: Atlas, 2015.

MATARAZZO, Dante. C. Análise financeira de balanços: uma abordagem básica e gerencial. 5 ed. São Paulo: Atlas, 1998.

MOSSIMANN, Clara Pellegrinello; FISCH, Sílvio. Controladoria: seu papel na administração de empresa. 2 ed. São Paulo: Atlas, 1999.

NAKAGAWA, Masauyki. Introdução à Controladoria: conceitos, sistemas e implementação. São Paulo: Atlas, 1993.

NASCIMENTO, Auster Moreira; REGINATO, Luciane. Controladoria: Um enfoque na eficácia organizacional. 2 ed. São Paulo: Atlas, 2009.

NASCIMENTO, Auster Moreira; REGINATO Luciane. Controladoria: instrumento de apoio ao processo decisório. São Paulo: Atlas, 2010.

2015.

Controladoria: Instrumento de apoio ao processo decisório. 2 ed. São Paulo: Atlas, 
OLIVEIRA, Luis Martins de. Controladoria: conceitos e aplicações. São Paulo: Futura, 1998.

OLIVEIRA, Luiz Martins de. Controladoria Estratégica. 6 ed. São Paulo: Atlas, 2010.

OLIVEIRA, Luis Martins de; PEREZ Jr., José Hernandez, SILVA; Carlos Alberto dos Santos. Controladoria Estratégica. São Paulo: Atlas, 2002.

Controladoria Estratégica. 2 ed. São Paulo: Atlas, 2004.

. Controladoria estratégica. 6 ed. São Paulo: Atlas, 2010.

PADOVEZE, Clóvis Luís. Controladoria básica. 2 ed. São Paulo: Cengage Learning, 2003.

Controladoria Básica. 2 ed. São Paulo: Cengage Learning, 2010.

PADOVEZE, Clóvis Luís. Controladoria Estratégica Aplicada: conceitos, estrutura e sistema de informações. São Paulo: Cengage Learning, 2016.

PELEIAS, Ivam Ricardo. Controladoria: gestão eficaz utilizando padrões. São Paulo: Saraiva, 2002.

PEREZ JUNIOR, José Hernandez; PESTANA, Armando Oliveira; FRANCO, Sérgio Paulo Cintra. Controladoria de Gestão. São Paulo: Atlas, 1997.

PEREIRA, Maria Isabel; SANTOS, Sílvio Aparecido dos. Modelo de Gestão: uma análise conceitual. São Paulo: Pioneira - Thomson Learning, 2001.

SANTOS, José Luiz dos; SCHMIDT, Paulo. Fundamentos de controladoria. São Paulo: Atlas, 2006.

SROUR, Robert Henry. Ética empresarial: o ciclo virtuoso dos negócios. 3 ed. São Paulo: Elsevier, 2008.

Como citar este artigo (Formato ABNT):

LIMA, Emanoel Romário de; MACÊDO, Maria Erilúcia Cruz. O Papel Estratégico do Controller nas Organizações. Id on Line Rev.Mult. Psic., 2019, vol.13, n.43, p. 684-697. ISSN: 1981-1179.

Recebido: 23/11/2018;

Aceito: $24 / 11 / 2018$ 